$12-2007$

\title{
A Computer Model of Gluconeogenesis and Lipid Metabolism in the Perfused Liver
}

\author{
Elie Chalhoub \\ Cleveland State University \\ Richard W. Hanson \\ Case Western Reserve University \\ Joanne M. Belovich \\ Cleveland State University
}

Follow this and additional works at: https://engagedscholarship.csuohio.edu/encbe_facpub

Part of the Biomedical Engineering and Bioengineering Commons

How does access to this work benefit you? Let us know!

Publisher's Statement

https://doi.org/10.1152/ajpendo.00161.2007

\section{Repository Citation}

Chalhoub, Elie; Hanson, Richard W.; and Belovich, Joanne M., "A Computer Model of Gluconeogenesis and Lipid Metabolism in the Perfused Liver" (2007). Chemical \& Biomedical Engineering Faculty Publications. 160.

https://engagedscholarship.csuohio.edu/encbe_facpub/160

This Article is brought to you for free and open access by the Chemical \& Biomedical Engineering Department at EngagedScholarship@CSU. It has been accepted for inclusion in Chemical \& Biomedical Engineering Faculty Publications by an authorized administrator of EngagedScholarship@CSU. For more information, please contact library.es@csuohio.edu. 


\title{
A computer model of gluconeogenesis and lipid metabolism in the perfused liver
}

\author{
Elie Chalhoub, Richard W. Hanson, and Joanne M. Belovich
}

Chalhoub E, Hanson RW, Belovich JM. A computer model of gluconeogenesis and lipid metabolism in the perfused liver. Am J Physiol Endocrinol Metab 293: E1676-E1686, 2007. First published October 2, 2007; doi:10.1152/ajpendo.00161.2007._A mathematical model of the perfused rat liver was developed to predict intermediate metabolite concentrations and fluxes in response to changes in various substrate concentrations in the perfusion medium. The model simulates gluconeogenesis in the liver perfused separately with lactate and pyruvate and the combination of these substrates with fatty acids (oleate). The model consists of key reactions representing gluconeogenesis, glycolysis, fatty acid metabolism, tricarboxylic acid cycle, oxidative phosphorylation, and ketogenesis. Michaelis-Menten-type kinetic expressions, with control by ATP/ADP, are used for many of the reactions. For key regulated reactions (fructose-1,6-bisphosphatase, phosphofructokinase, pyruvate carboxylase, pyruvate dehydrogenase complex, and pyruvate kinase), rate expressions were developed that incorporate allosteric effectors, specific substrate relationships (e.g., cooperative binding), and/or phosphorylation/dephosphorylation using in vitro enzyme activity data and knowledge of the specific mechanisms. The model was independently validated by comparing model predictions with 10 sets of experimental data from 7 different published works, with no parameter adjustments. The simulations predict the same trends, in terms of stimulation of substrate uptake by fatty acid addition, as observed experimentally. In general, the major metabolic indicators calculated by the model are in good agreement with experimental results. For example, the simulated glucose/pyruvate mass yield is $43 \%$ compared with the average of $45 \%$ reported in the literature. The model accurately predicts the specific time constants of the glucose response (2.5-4 min) and the dynamic behavior of substrate and product fluxes. It is expected that this model will be a useful tool for analyzing the complex relationships between carbohydrate and fat metabolism.

liver; metabolism; mathematical model; gluconeogenesis; lipids

GLUCONEOGENESIS IN THE LIVER has been studied extensively over the past four decades, resulting in a better understanding of the factors that regulate the rates of glucose synthesis from various substrates and the effects of substances such as fatty acids and ethanol on this process. Despite this wealth of experimental data, the challenge remains to be able to predict how alterations in specific physiological stimuli will affect the distribution of fluxes in the liver and, in particular, the rate of hepatic gluconeogenesis.

Metabolic models of the liver can be divided into two broad categories: lumped models that consider the organ as wellmixed and distributed-in-space models that consider the heterogeneous nature of the organ. Garfinkel and colleagues $(1,3)$ developed the first well-recognized model of liver metabolism using detailed in vitro-based kinetic expressions. Their model of gluconeogenesis consisted of kinetic expressions for reactions taking place between phosphoenolpyruvate (PEP) and glucose, with the net flux through enolase (interpreted from experimental data under a variety of substrates) taken as the input to the model. Because the reactions kinetics of pyruvate carboxylase (PC) and liver-type pyruvate kinase (PK-L) were not considered, the futile cycling that occurs through these reactions was neglected. Moreover, the model lacked ATP and redox balances, the ketogenic reactions, and some of the dehydrogenase reactions that are critical to controlling the relationships between lipid metabolism and gluconeogenesis. Furthermore, this work was done before knowledge about important regulator effects, such as cAMPmediated phosphorylation of key regulatory enzymes like PK-L and fructose-1,6-bisphosphatase (FBPase) and the allosteric effects of fructose-2,6-bisphosphate (F-2,6- $\left.P_{2}\right)$. Using a similar approach, Bergman and El Refai (6) simulated glycogen synthesis and degradation and glucose output at fixed rates of gluconeogenesis. A subset of glycolytic and glycogenolytic reactions around glucose 1-phosphate, glucose 6-phosphate (G-6-P), and fructose 6-phosphate (F-6- $P$ ) was the subject of a power law formalism model applied to an in vitro experimental system using tissue extracts (59). Hepatic tricarboxylic acid (TCA) cycle flux was modeled as an isolated subsystem, using parameter values that were time-dependent and adjusted for each substrate $(24,25)$.

More recent modeling approaches have eschewed dynamic models for ones based on steady state, without the need for reaction kinetics. These include the steady-state flux balance analysis (FBA) approach with optimization of a presumed objective function (including energy constraints; see Refs. 11 and 41), FBA with Fischer discriminant analysis (13), and the FBA and thermodynamic constraint-based model (5). All of these approaches consist of a comprehensive system of reactions describing hepatic metabolism, and they provide insight into the distribution of fluxes at various steady states. The approach by Beard and Qian (5) is particularly interesting since it uses both FBA and thermodynamic constraints; even without kinetic parameters, it can predict metabolite concentrations at steady state and analyze the control structure. However, these FBA-based methods require the use of experimental measurements of fluxes as inputs to the model and, since they lack reaction kinetics, have limited predictive value.

The liver, in reality, has a very heterogeneous organization, and several published works have considered its distributed- 
in-space nature by representing the liver as a system of parallel tubular reactors $(49,55)$ for prediction of the elimination rates of specific drugs. More recently, a distributed-in-space model, which employs a simplified reaction system representing gluconeogenesis and associated pathways and takes into account heterogeneity in enzyme distribution, i.e., "zonation" (32), has been used to investigate the role of zonation in the relative rates of glycolysis and gluconeogenesis along the sinusoid in the fasted, the resting state, and to study the effect of high-intensity exercise on glucose production (12). Although this distributed model uses available information concerning liver structure and enzyme distributions, there are few data available to validate the model's predictions at this level of detail. Most of the available data are derived from the entire organ, such as measurements of the concentrations of intermediates from tissue homogenates, metabolic flux determinations from arterial-venous differences (for in vivo), or input-perfusate concentrations (for perfused liver), with or without tracers. This makes it nearly impossible to thoroughly validate a distributed model. Furthermore, most measurements of enzymatic kinetic parameters in liver also represent the average value for the tissue.

In this work, we have developed a lumped model of hepatic metabolism, with an emphasis on gluconeogenesis and fatty acid metabolism. Although the model was kept as simple as possible to achieve tractability, reactions are included as necessary to account for the relationship between gluconeogenesis and lipid metabolism. Additional reactions, such as those occurring mainly in glycolysis, are included to increase the flexibility of the model for future applications. MichaelisMenten-type kinetic expressions were used for many of the reactions. However, the exclusive use of these expressions was inadequate for achieving the expected physiological results. For key regulated reactions [FBPase, phosphofructokinase (PFK), PC, pyruvate dehydrogenase complex (PDC), and PK], rate expressions were used that incorporate allosteric effectors, specific substrate relationships (e.g., cooperative binding), and/or phosphorylation/dephosphorylation and were developed using in vitro enzyme activity data and knowledge of the specific mechanisms.

The model is first used to represent the 24-h-fasted rat liver in vivo. Because many of the most well-controlled, data-rich experiments available in the literature have been performed with the perfused liver, we then modified the model to account for the conditions of the ex vivo liver in a recirculated perfusion system. With the same set of kinetic parameters, this model is used to predict the effect of fatty acid uptake on gluconeogenesis rates during separate lactate and pyruvate perfusions. Our simulations are then compared with experimental data available from the literature.

\section{METHODOLOGY}

Metabolic pathway. The metabolic pathways considered in the model development are glycolysis, gluconeogenesis, the TCA cycle, fatty acid oxidation, fatty acid synthesis, ketogenesis, oxidative phosphorylation, and glycogen degradation (Fig. 1). Each pathway is represented by a few key reactions, mainly those essential for defining the relationships between lipid metabolism and gluconeogenesis.

The rate expressions are given in Supplemental Table S1 (Supplemental data for this article are available online at the American Journal of Physiology-Endocrinology and Metabolism website). The rate mechanism for transport between the blood and tissue domains is

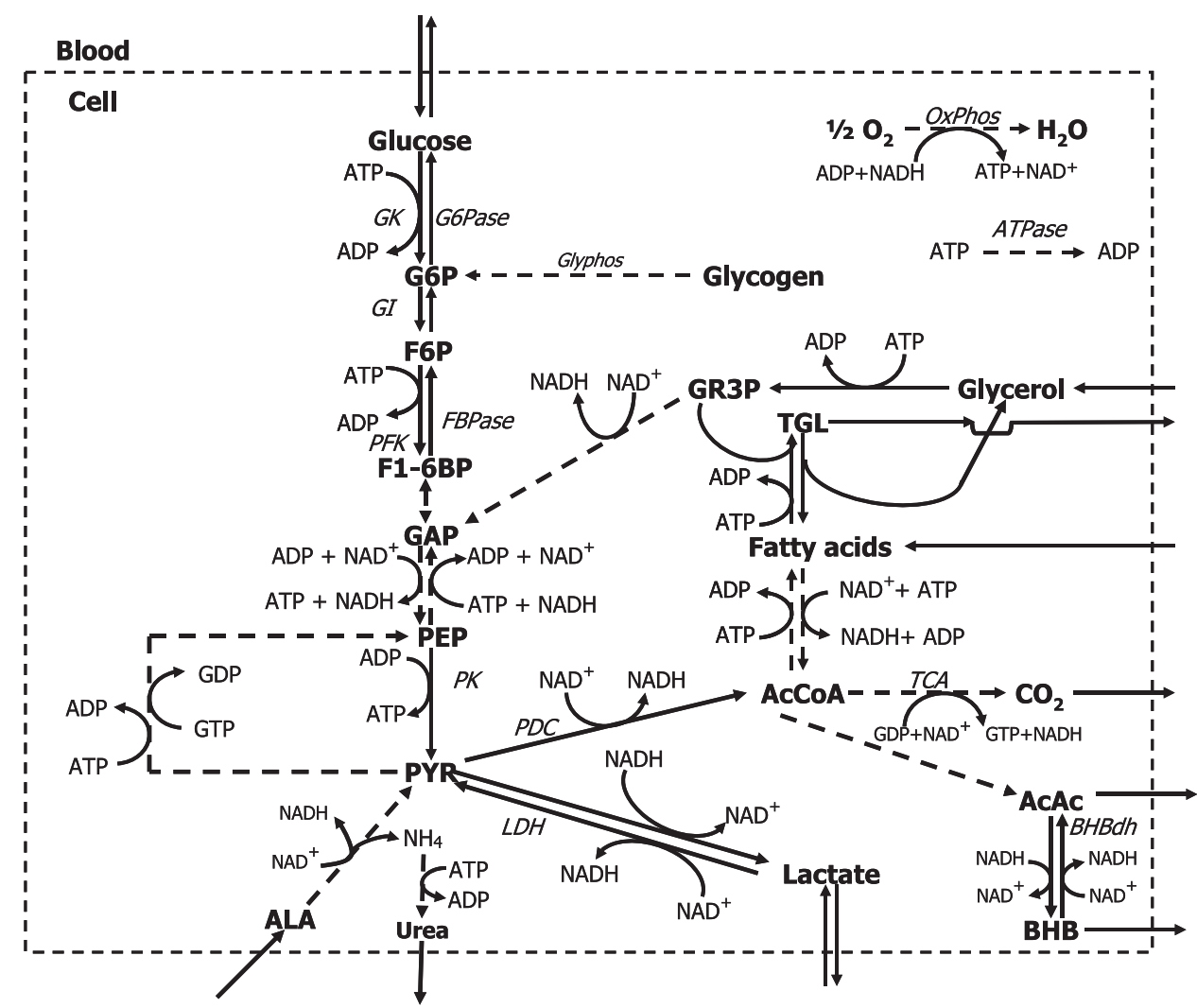

Fig. 1. Reaction network considered in tissue model. Broken lines indicate a series of reactions that have been lumped together. Detailed stoichiometry for each reaction shown here is given in Supplemental Table S1. The ATPase reaction represents the total of all ATP-utilizing reactions that are not considered explicitly in the model. GK, glucokinase; G-6-Pase, glucose-6-phosphatase; Glyphos, glycogen phosphorylase; OxPhos, oxidative phosphorylation; PK, pyruvate kinase; PC, pyruvate carboxylase; PDC, pyruvate dehydrogenase complex; LDH, lactate dehydrogenase; BHBdh, $\beta$-hydroxybutyrate dehydrogenase; GAP, glyceraldehyde 3-phosphate; GR-3-P, glycerol 3-phosphate; PEP, phosphoenolpyruvate; AcAc, acetoacetate; BHB, $\beta$-hydroxybutyrate; AcCoA, acetyl-CoA; ALA, alanine. 
described by facilitated diffusion. The kinetic expressions for some of the relatively irreversible reactions are expressed by simple Michaelis-Menten kinetics, with modulation by ADP/ATP and $\mathrm{NADH} / \mathrm{NAD}^{+}(\mathrm{RS})$, as relevant. Reversible, near-equilibrium reactions are represented by a simplified form of a reversible, ping-pong mechanism, with the Haldane equation used to relate kinetic parameter values at near-equilibrium and to ensure consistency with thermodynamic constraints.

The kinetic parameters were generally obtained either from in vitro kinetic studies with purified enzymes, by calculation from in vivo data and the assumed rate expression, or a combination of these methods. For reversible reactions, the equilibrium constants and maximal velocities $\left(V_{\max }\right)$ were obtained from the literature; the forward Michaelis constant $\left(K_{\mathrm{m}}\right)$ was set equal to the product of the substrate concentrations, and the reverse $K_{\mathrm{m}}$ was calculated based on the in vivo flux and concentrations. Michaelis-Menten kinetics were often used as simplifications for a series of reactions and do not necessarily represent a specific enzyme. Most often, parameters were calculated from in vivo data rather than from in vitro kinetic studies of purified enzymes. The $K_{\mathrm{m}}$ was set equal to the approximate steady-state concentration of the corresponding substrate, whereas the $V_{\max }$ was calculated by setting the reaction expression equal to the corresponding in vivo flux expected during the 24-h-fasted state (given in Table 1). The specific approach used for each reaction is indicated in Supplemental Table S1.

In some cases, Michaelis-Menten and reversible kinetics, as described above, were found to be inadequate for achieving the expected physiological responses during gluconeogenesis and lipid metabolism. Thus the rate expressions were modified to take into account allosteric effectors, specific substrate relationships (e.g., cooperative binding), and phosphorylation/dephosphorylation. Detailed kinetic expressions were developed for five regulated reactions (FBPase, PFK, PC, PDC, and PK) using in vitro enzyme activity data and knowledge of the specific mechanisms gleaned from the literature (Supplemental Table S1). The rate expression of FBPase includes the effect of phosphorylation and dephosphorylation by means of cAMPdependent protein kinase, along with AMP as an uncompetitive inhibitor and F-2,6- $P_{2}$ as a competitive inhibitor. The PFK expression is based on the bi-bi mechanism, where ATP acts as substrate inhibitor while AMP and F-2,6- $P_{2}$ are activators. The kinetics of the lumped reaction $R_{P Y R} \rightarrow$ PEP, where PYR is pyruvate, is represented by the kinetics of the PC reaction, with activation by acetyl-CoA (AcCoA) and inhibition by ADP, where ADP plays the role of uncompetitive inhibition with respect to pyruvate and competitive inhibition with respect to ATP. The PK expression reflects phosphorylation as an allosteric effect mediated by cAMP-dependent protein kinase, inhibition by both ATP and alanine, and activation by fructose-1,6-bisphosphate $\left(\mathrm{F}-1,6-\mathrm{P}_{2}\right)$. One of the PK model parameters $\left(\mathrm{K}_{\mathrm{F}-1,6-\mathrm{P}_{2}, \mathrm{PK}}\right)$ was modified significantly from the original kinetic model (F. Pusca and $\mathrm{J}$. Belovich, unpublished observation) to provide the expected fluxes at physiological concentrations of allosteric regulators not considered in the previous in vitro studies. The rate kinetics of PDC were developed to account for inhibition by AcCoA, the ATP-to-ADP ratio, and the $\mathrm{NADH}$-to-NAD ${ }^{+}$ratio and the effect of inhibition by phosphorylation of the enzyme by pyruvate dehydrogenase kinase that is mediated through ATP. Kinetic parameters were obtained by fitting the reaction expressions to in vitro kinetic data using least-squares regression.

Although cytosolic-mitochondrial compartmentation is not considered specifically, the mitochondrial redox state is significantly different from the cytoplasmic redox state, and this difference between the two compartmental concentrations was found to significantly affect reaction rates involving NADH-coupled enzymes. A pseudomitochondrial compartment was established only for NADH/NAD ${ }^{+}$, with the assumption that the mitochondrial redox ratio, $\mathrm{RS}_{\mathrm{m}}$ [defined as $\mathrm{C}_{\mathrm{NADH}(\mathrm{m})} / \mathrm{C}_{\mathrm{NAD}^{+}(\mathrm{m})}$, where $\mathrm{C}_{\mathrm{NADH}(\mathrm{m})}$ and $\mathrm{C}_{\mathrm{NAD}^{+}(\mathrm{m})}$ are the mitochondrial concentrations of $\mathrm{NADH}$ and $\mathrm{NAD}^{+}$, respectively], is in equilibrium with the cytosolic ratio $\mathrm{RS}\left[\mathrm{C}_{\mathrm{NADH}(\mathrm{c})} / \mathrm{C}_{\mathrm{NAD}^{+}(\mathrm{c})}\right.$, where
Table 1. Steady-state results

\begin{tabular}{|c|c|c|c|}
\hline & Calculated & Experimental & Ref. No. \\
\hline \multicolumn{4}{|l|}{$\begin{array}{c}\text { Metabolite concentrations, } \\
\mu \mathrm{mol} / \mathrm{gww} \text { hep }\end{array}$} \\
\hline Glc,tissue & 6.3 & $4.5-6$ & 7 \\
\hline Glc,blood & 5.55 & $5.07-5.48$ & 15 \\
\hline F-6-P & 0.039 & 0.046 & 7 \\
\hline F-1,6- $P_{2}$ & 0.0023 & 0.016 & 7 \\
\hline G-6- $P$ & 0.087 & 0.102 & 7 \\
\hline Glycogen & 109 & $109-175$ & 7 \\
\hline GAP & 0.015 & 0.021 & 57,66 \\
\hline GR-3-P & 0.25 & 0.31 & 7 \\
\hline PEP & 0.0061 & 0.05 & 7 \\
\hline \multicolumn{4}{|l|}{ PYR } \\
\hline Blood & 0.024 & 0.062 & 15 \\
\hline Tissue & 0.023 & 0.059 & $7,34,57$ \\
\hline \multicolumn{4}{|l|}{ LAC } \\
\hline Blood & 0.59 & $0.85-1.2$ & 15 \\
\hline Tissue & 0.46 & $0.35-0.95$ & $7,34,66$ \\
\hline \multicolumn{4}{|l|}{$\mathrm{AcAc}$} \\
\hline Blood & 1.47 & $0.68-0.99$ & 15,29 \\
\hline Tissue & 1.61 & $0.5-0.78$ & $7,34,66$ \\
\hline \multicolumn{4}{|l|}{ BHB } \\
\hline Blood & 2.07 & $0.85-1.7$ & 15,29 \\
\hline Tissue & 5.6 & 2.23 & $7,34,66$ \\
\hline \multicolumn{4}{|l|}{ ALA } \\
\hline Blood & 0.23 & 0.56 & 15 \\
\hline Tissue & 0.18 & 0.475 & 7 \\
\hline $\mathrm{AcCoA}$ & 0.13 & 0.13 & 7 \\
\hline ATP & 3.46 & 3.43 & 7,27 \\
\hline $\mathrm{ATP}+\mathrm{ADP}+\mathrm{AMP}$ & 5.07 & $3.68-5.2$ & 7,27 \\
\hline $\mathrm{NADH}(\mathrm{m}) / \mathrm{NAD}(\mathrm{m})^{+}$ & 0.25 & 0.18 & 66 \\
\hline $\mathrm{NADH}(\mathrm{c}) / \mathrm{NAD}(\mathrm{c})^{+}$ & 0.0021 & 0.0017 & 57,66 \\
\hline \multicolumn{4}{|l|}{$\begin{array}{l}\text { Fluxes, } \mu \mathrm{mol} \cdot \mathrm{gww} \\
\mathrm{hep}^{-1} \cdot \mathrm{min}^{-1}\end{array}$} \\
\hline$J_{\mathrm{GLC}, \mathrm{b}-\mathrm{t}, \mathrm{net}}$ & 1.11 & $1.2-1.9$ & $30,40,53$ \\
\hline$J_{\mathrm{LAC}, \mathrm{b}-\mathrm{t}, \mathrm{net}}$ & -1.38 & -1.54 & 15 \\
\hline$J_{\mathrm{BHB}, \mathrm{b}-\mathrm{t}, \mathrm{net}}$ & 1.09 & 0.93 & 15 \\
\hline$J_{\mathrm{ALA}, \mathrm{b}-\mathrm{t}, \mathrm{net}}$ & -0.59 & -0.64 & 15 \\
\hline$J_{\mathrm{PYR}, \mathrm{b}-\mathrm{t}, \mathrm{net}}$ & -0.12 & -0.14 & 15 \\
\hline$J_{\mathrm{FFA}, \mathrm{b}-\mathrm{t}, \mathrm{net}}$ & -0.87 & -0.8 & 15 \\
\hline$J_{\mathrm{GLR}, \mathrm{b}-\mathrm{t}, \mathrm{net}}$ & -0.96 & -0.14 & 15 \\
\hline $\mathrm{GK}$ & 0.57 & & \\
\hline G-6-Pase & 1.68 & & \\
\hline GI & 1.07 & & \\
\hline $\mathrm{GAP} \rightarrow \mathrm{F}-1,6-P_{2}$ & 2.15 & & \\
\hline FBPase & 1.08 & & \\
\hline PFK & 0.007 & & \\
\hline $\mathrm{PEP} \rightarrow \mathrm{GAP}$ & 2.08 & & \\
\hline PK & 0.0003 & 5.56 & 30 \\
\hline $\mathrm{PYR} \rightarrow \mathrm{PEP}$ & 2.09 & $3-3.6,7.9$ & 45,30 \\
\hline LDH & 1.26 & & \\
\hline $\mathrm{GLR} \rightarrow \mathrm{GR}-3-P$ & 0.099 & & \\
\hline GR-3- $P \rightarrow \mathrm{GAP}$ & 0.06 & & \\
\hline FAT_syn & 0.71 & & \\
\hline $\mathrm{FFA} \rightarrow \mathrm{AcCoA}$ & 0.86 & & \\
\hline TG_f & 0.11 & & \\
\hline $\mathrm{AcC}-\mathrm{A} \rightarrow \mathrm{AcAc}$ & 4.83 & & \\
\hline OxPhos & 8.20 & & \\
\hline TCA & 1.37 & 1.75 & 30 \\
\hline$J_{\mathrm{TG}, \mathrm{b}-\mathrm{t}, \mathrm{net}}$ & 0.03 & & \\
\hline PDC & 0.0023 & & \\
\hline
\end{tabular}

Steady-state results, at the overnight fasted state, experimental and calculated using Eqs. 1 and 2, with upstream blood concentrations as follows: $\mathrm{C}_{\mathrm{Clc}}^{*}=4.6 \mathrm{mM}(7) ; \mathrm{C}_{\mathrm{LAC}}^{*}=1.7 \mathrm{mM}(7) ; \mathrm{C}_{\mathrm{PYR}}^{*}=0.12 \mathrm{mM}(7) ; \mathrm{C}_{\mathrm{FFA}}^{*}=1.5$ $\mathrm{mM}(7,8) ; \mathrm{C}_{\mathrm{ACAc}}^{*}=0.43 \mathrm{mM}(7,8) ; \mathrm{C}_{\mathrm{BHB}}^{*}=1.2 \mathrm{mM}(8)$. Physical parameters used in Eqs. 1-2 are as follows: $\mathrm{F}_{\text {blood }}=6.57 \mathrm{ml} / \mathrm{min} ; \mathrm{V}_{\text {tissue }}=5.25 \mathrm{~cm}^{3}(12)$; $\mathrm{V}_{\text {blood }}=1.03 \mathrm{~cm}^{3}(12)$. Reaction rates $\left(\mathrm{R}_{i}\right)$ and transport rates $\left(J_{\mathrm{i}, \mathrm{b}-\mathrm{t}}\right)$ are given in Supplemental Table S1 (+, production rate; -, uptake rate). See text for definitions. 
$\mathrm{C}_{\mathrm{NADH}(\mathrm{c})}$ and $\mathrm{C}_{\mathrm{NAD}^{+}(\mathrm{c})}$ are the cytosolic concentrations of NADH and $\mathrm{NAD}^{+}$, respectively]; this assumption is expressed as $\mathrm{RS}_{\mathrm{m}}=$ $K_{\text {eq,RS }} \times$ RS. The equilibrium constant $K_{\text {eq,Rs }}$ is calculated from the ratios of free cytosolic and mitochondrial $\mathrm{C}_{\mathrm{NADH}} / \mathrm{C}_{\mathrm{NAD}^{+}}$at the fasted steady state, obtained from measurements of $\mathrm{C}_{\mathrm{LAC}} / \mathrm{C}_{\mathrm{PYR}}$ (where LAC indicates lactate) and $\mathrm{C}_{\mathrm{BHB}} / \mathrm{C}_{\mathrm{AcAc}}$, (where $\mathrm{BHB}$ indicates $\beta$-hydroxybutyrate and AcAc is acetoacetate), respectively, at equilibrium.

Model of the in vivo liver. The liver is represented by two wellmixed domains representing the tissue and blood compartments, with mass balances for each metabolite $i$ given by:

$$
\begin{gathered}
\frac{\mathrm{dC}_{i, \text { tissue }}}{\mathrm{d} t}=J_{i, \mathrm{~b}-\mathrm{t}}+\sum_{j} \mathrm{R}_{i, j} \\
\frac{\mathrm{dC}_{i, \text { blood }}}{\mathrm{d} t}=\left(\mathrm{C}_{i}^{*}-\mathrm{C}_{i, \text { blood }}\right) \frac{\mathrm{F}_{\text {blood }}}{\mathrm{V}_{\text {blood }}}-J_{i, \mathrm{~b}-\mathrm{t}}\left(\frac{\mathrm{V}_{\text {tissue }}}{\mathrm{V}_{\text {blood }}}\right)
\end{gathered}
$$

where $C_{i}^{*}$ is the concentration of each metabolite in the blood upstream of the liver (calculated from a weighted average of portal vein and hepatic artery concentrations; Table 1$) ; C_{i, \text { tissue }}$ and $C_{i, \text { blood }}$ are concentrations of metabolite $i$ in the tissue and blood domains, respectively; $J_{i, \mathrm{~b}-\mathrm{t}}$ is the transport rate between the blood and tissue domains $\left(\mu \mathrm{mol} \cdot \mathrm{g}\right.$ tissue $\left.{ }^{-1} \cdot \mathrm{min}^{-1}\right) ; \mathrm{R}_{i, j}$ is the reaction rate of each reaction $j$ with metabolite $i$ as substrate or product; and $\mathrm{F}_{\text {blood }}$ is the blood flow rate through the liver. The ratio of tissue volume to blood volume $\left(\mathrm{V}_{\text {tissue }} / \mathrm{V}_{\text {blood }}\right)$ is used for conversion of units of $J_{i, \mathrm{~b}-\mathrm{t}}$ from tissue volume units to blood volume units.

The mass balance equation of the tissue $(E q .1)$ is written for each intermediate within the cell shown in the metabolic pathway in Fig. 1 (i.e., glucose, lactate, alanine, acetoacetate, $\beta$-hydroxybutyrate, glycogen, glycerol, triglyceride, fatty acid, pyruvate, ATP, NADH, G-6- $P$, F-6- $P$, F-1,6- $P_{2}$, glyceraldehyde 3-phosphate, PEP, and AcCoA), using the stoichiometry given in Supplemental Table S1. The mass balance for GTP is included within the balance for ATP by assuming a fast equilibration of neucleoside diphosphokinase. Equation 2 is written for every intermediate that occurs in the blood, as shown in Fig. 1 (i.e., glucose, lactate, alanine, acetoacetate, $\beta$-hydroxybutyrate, glycerol, triglyceride, fatty acid, and pyruvate). Equations 1 and 2 were solved simultaneously at steady state. Because enzyme kinetic parameters were in general obtained from liver extracted from fasted rats, and the upstream blood concentrations $\left(\mathrm{C}_{i}^{*}\right)$ were obtained from blood samples from fasted rats, we assume that this simulation represents the conditions in vivo for a liver from a 24-h-fasted rat.

Model of the perfused liver. The model was then modified to represent the liver perfused ex vivo in a recycling perfusion system, as used by Williamson et al. (64) and others (see Fig. 2). The tissue mass balance is given by $E q$. 1 . The mass balance in the blood domain is given by:

$$
\frac{\mathrm{dC}_{i, \text { blood }}}{\mathrm{d} t}=\left(\mathrm{C}_{i, \text { perfusate }}-\mathrm{C}_{i, \text { blood }}\right) \frac{\mathrm{F}_{\text {perfusate }}}{\mathrm{V}_{\text {blood }}}-J_{i, \mathrm{~b}-\mathrm{t}}\left(\frac{\mathrm{V}_{\text {tissue }}}{\mathrm{V}_{\text {blood }}}\right)
$$

where $\mathrm{C}_{i \text {,perfusate }}$ is the concentration of metabolite $i$ in the perfusion medium and $F_{\text {perfusate }}$ is the perfusate flow rate. Because the content of the blood domain is actually the saline perfusion medium rather than blood, Eq. 3 is only written for those metabolic intermediates expected to occur in the perfusate (i.e., glucose, lactate, alanine, acetoacetate, $\beta$-hydroxybutyrate, pyruvate). The perfusion medium vessel, which we also assumed to be well-mixed, is represented by the following mass balance for each metabolic intermediate that exists in the blood domain:

$$
\frac{\mathrm{dC}_{i, \text { perfusate }}}{\mathrm{d} t}=\left(\mathrm{C}_{i, \text { blood }}-\mathrm{C}_{i, \text { perfusate }}\right) \frac{\mathrm{F}_{\text {perfusate }}}{\mathrm{V}_{\text {perfusate }}}
$$

where $V_{\text {perfuate }}$ is the volume of the perfusion medium.

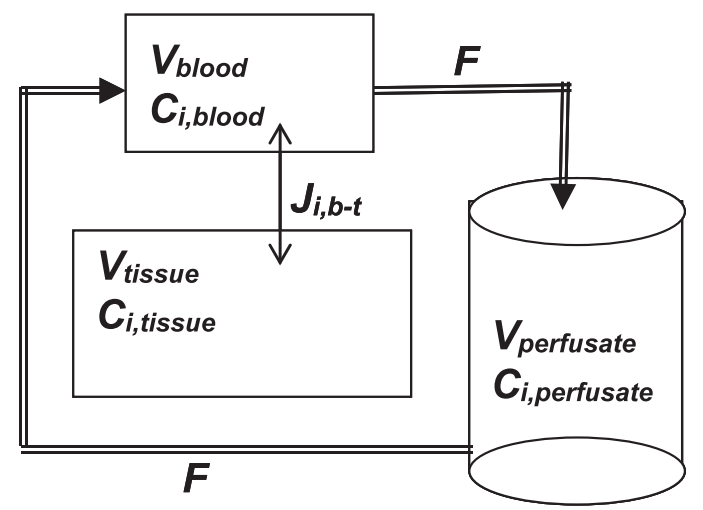

Fig. 2. Schematic of perfusion system that is the basis for the mathematical model. $\mathrm{C}_{i, \text { tissue }}$ and $\mathrm{C}_{i \text {,blood }}$, concentrations of metabolite $i$ in the tissue and blood domains, respectively; $J_{i, \mathrm{~b}-\mathrm{t}}$, transport rate between the blood and tissue domains; $\mathrm{F}$, flow; $\mathrm{V}_{\text {perfusate, }}$ volume of the perfusion medium; $\mathrm{C}_{\mathrm{i} \text {,perfusate, }}$ concentration of metabolite $i$ in the perfusion medium.

The quantities $\mathrm{F}_{\text {perfusate }}$ and $\mathrm{V}_{\text {perfusate }}$ in $E q .4$ are assigned values that match the specific experimental conditions from the literature that are being simulated.

It is generally recognized that the in vivo environment of an enzyme may be different from the in vitro experimental conditions from which the parameters are determined. Thus parameter values (Supplemental Table S1) were fine tuned to within $\pm 10 \%$ of their original values using the parameter estimation method of generalized reduced gradient, nonlinear optimization to fit the dynamic solution of Eqs. 1, 3, and 4 to the experimental lactate perfusion data of Williamson et al. (64) (Fig. 3). Three exceptions to this $\pm 10 \%$ constraint were found to be necessary to achieve the expected physiological results: $K_{\mathrm{F}-1,6-P_{2}, \mathrm{PK}, \mathrm{FBP} \text { ase }}$ was decreased $16 \%, K_{\mathrm{cAMP}, \mathrm{FBP}}$ ase was decreased $20 \%$, and $K_{\mathrm{m}, \mathrm{PEP}, \mathrm{GAP}}$ (where GAP is glyceraldehyde 3-phosphate) was decreased $90 \%$. This last parameter appears in the kinetic expression for the lumped reversible reaction $R_{P E P \leftrightarrow G A P}$. The large change in this parameter value indicates that the method of setting the $K_{\mathrm{m}}$ equal to the substrate concentration does not yield the expected results at physiological conditions for this reaction.

\section{RESULTS}

The model was first solved at conditions representing the in vivo 24-h-fasted state, using the kinetic parameters in Supplemental Table S1 and the physical parameters and upstream blood concentrations given in the legend of Table 1. The steady-state results are shown in Table 1 compared with experimental values available from the literature. In general, there is excellent agreement between calculated and experimental values, with the exceptions of F-1,6- $P_{2}$ and PEP, which are significantly lower than the in vivo measurements (which are already very low), and the flux through PK, which becomes completely inhibited in the model at this state.

The model was then used to simulate the lactate perfusion protocol of Williamson et al. (64) using the same set of kinetic parameters used in the in vivo model (Supplemental Table S1, as described above), with input functions and initial conditions given in Table 2. The simulation results compared with their experimental data are shown in Fig. 3. The first $30 \mathrm{~min}$ represents the liver, just removed from the animal and perfused with saline. The replacement of the blood with saline, which contains no substrate, results in large concentration gradients of metabolites such as glucose, $\beta$-hydroxybutyrate, and acetoacetate; this leads to the very brief spikes in release of these 
Glucose production

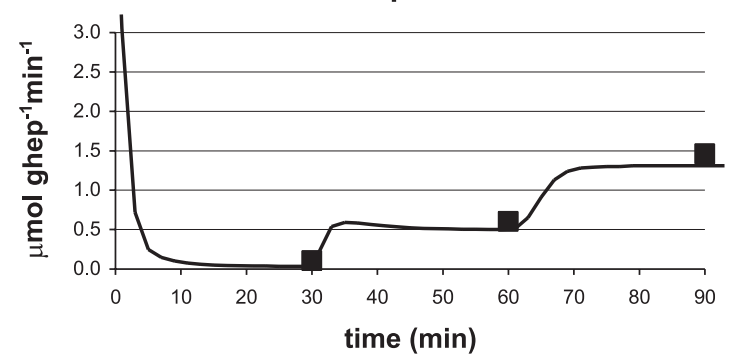

Lactate uptake

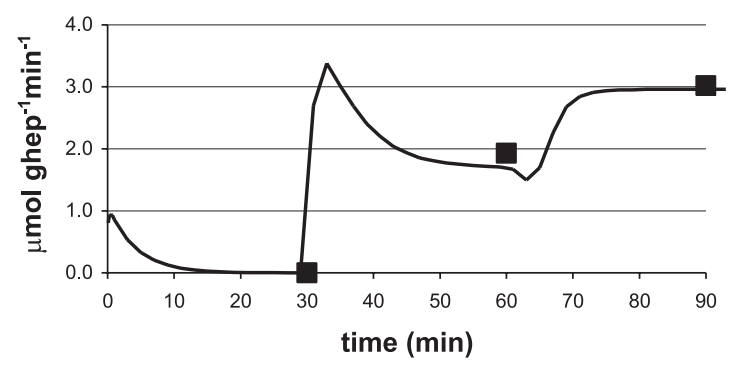

BHB production
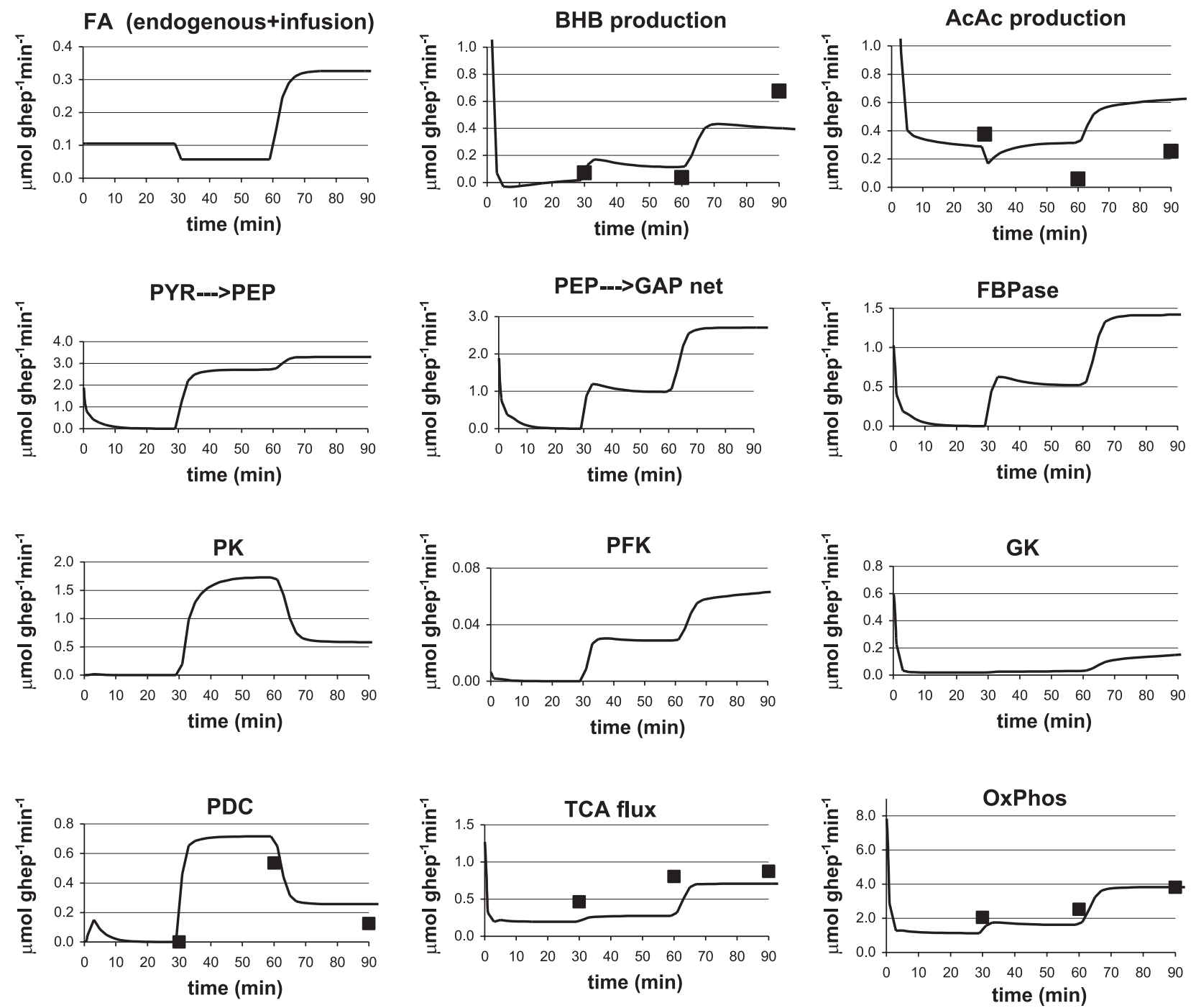

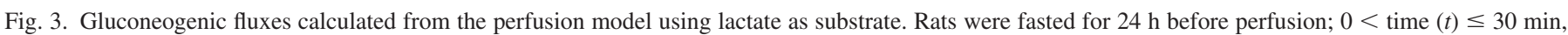

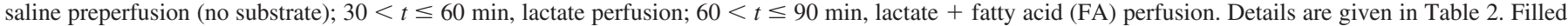

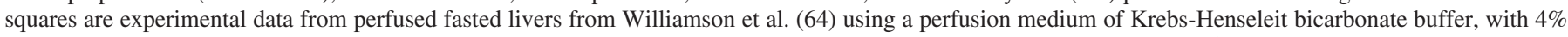

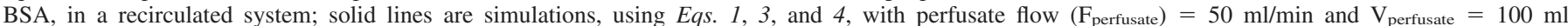

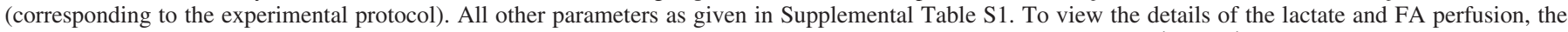

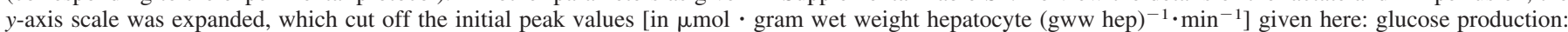
7.4; BHB production: 2.1; AcAc production: 6.0. PYR, pyruvate; FBPase, fructose-1,6-bisphosphatase; PFK, phosphofructokinase; TCA, tricarboxylic acid.

substances from the tissue. Some of the glucose production also results from gluconeogenesis from endogenous substrates and a small amount from glycogenolysis. Lactate uptake drops quickly to zero because of the absence of substrate in the perfused saline.
The simulated transition from saline perfusion to lactate perfusion begins at time $(t)>30 \mathrm{~min}$. As expected, lactate uptake increases quickly and overshoots before settling to a steady-state value. This overshoot results from stimulation of lactate transport by the large concentration gradient between 


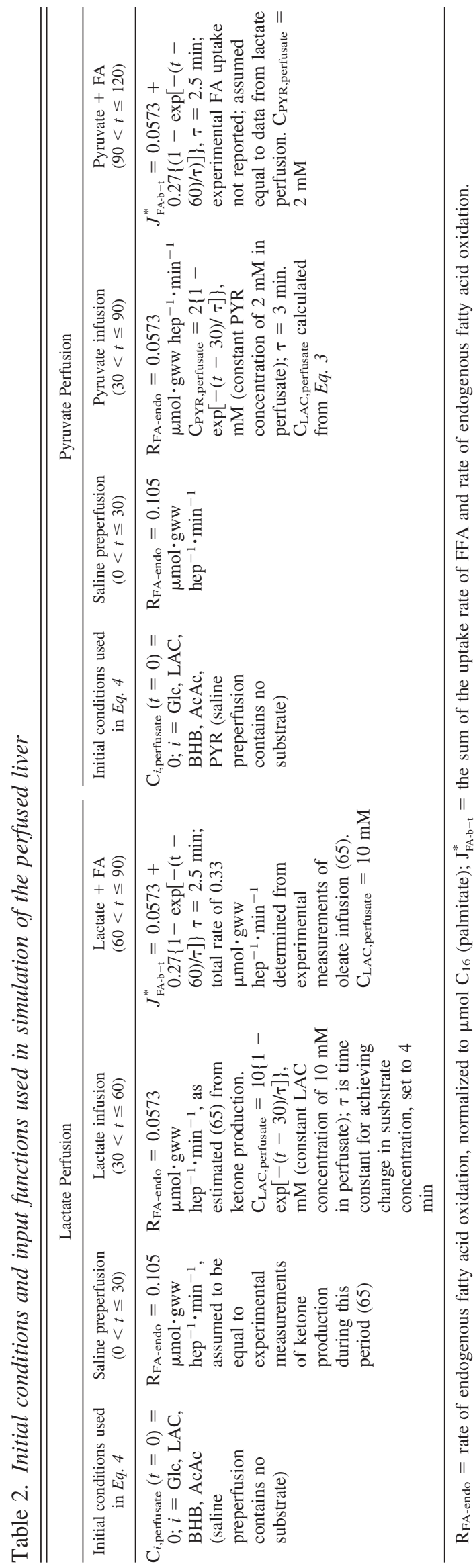

the perfusate and tissue. At steady state, $\sim 50 \%$ of the lactate (by mass) is converted to glucose, according to both the simulation and experimental data. According to the reported experimental data, the remaining carbon goes in the TCA cycle for oxidation. Our model underestimates TCA flux by $\sim 50 \%$ and instead overestimates total ketone body ( $\beta$-hydroxybutyrate and acetoacetate) production. Futile cycling through the PFK-FBPase system accounts for $10 \%$ of the net gluconeogenic flux. Although the exact amount of this futile cycling in vivo is difficult to quantify, it has been reported that, in the fasted state, there is essentially no futile cycling (31).

Infusion with fatty acids is simulated beginning at $t>60$ min (Fig. 3). The additional energy generated by hepatic fatty acid oxidation increases the gluconeogenic flux so that both glucose production and lactate uptake increase, with close correspondence to the experimental data. The increased AcCoA concentration, derived from the oxidation of exogenous fatty acids, inhibits flux through PDC and increases flux through PC, while increasing ketogenesis, as expected. The oxidative phosphorylation also increases, similar to reported values.

The sensitivities of glucose production and lactate uptake were investigated for the four parameters $\left(K_{\mathrm{m}, \mathrm{PEP}, \mathrm{GAP}}\right.$, $K_{\mathrm{F}-1,6-P_{2}, \mathrm{PK}}, K_{\mathrm{F}-1,6-P_{2}, \mathrm{FBP} a s e}$, and $\left.K_{\mathrm{cAMP}, \mathrm{FBPase}}\right)$ that needed to be modified significantly from the original values obtained from in vitro or in vivo data. Figure 4 shows the dynamic flux profiles during lactate perfusion, where each parameter is varied individually, while all other parameters are held constant at the values given in Supplemental Table S1. The results are most sensitive to $K_{\mathrm{F}-1,6-P_{2}, \text { FBPase }}, K_{\mathrm{cAMP}, \mathrm{FBP} P a s e}$, and $K_{\mathrm{F}-1,6-P_{2}, \mathrm{PK}}$, but sensitivity is still relatively low at these conditions, since a doubling of the parameter leads to, at most, a $10 \%$ change in the flux of glucose and lactate.

The model, with the same set of parameters as given in Supplemental Table S1, was then used to simulate a variety of pyruvate, lactate, and fatty acid perfusion conditions, with the results compared with independent experimental data sets from the literature. Figure 5 shows the results of pyruvate perfusions. Although the model underestimates both the pyruvate uptake and glucose production compared with experimental values, the yields of glucose from pyruvate calculated from the model are nearly the same as those reported by Williamson et al. in Fig. $5 A$ in which $48 \%$ by mass of pyruvate is converted to glucose experimentally while the model predicts $45 \%$ conversion; in Fig. 5B, the experimental conversion is $50 \%$ while the calculated conversion is $41 \%$. The addition of fatty acids at $t=90 \mathrm{~min}$ (Fig. 5B) increases pyruvate uptake, glucose production, and lactate production with trends similar to the published experimental data (64).

Figure 6 shows the calculated glucose production compared with experimental data as reported in two separate published works using lactate as substrate $(22,27)$. The simulations are again using the same parameters given in Supplemental Table $\mathrm{S} 1$. Although the model underestimates glucose production by $\sim 40 \%$ in Fig. 6, $A$ and $C$, the prediction is nearly identical to the experiment in Fig. $6 B$.

The accuracy of the model's dynamic response for both lactate and pyruvate perfusions is evaluated in Fig. 7. In the retrograde perfusion (9), the time constants for the glucose response were 2.5-4 min for both the addition and removal of substrate, with similar response times calculated by the model. 
Fig. 4. Simulations using the perfusion model, using parameters as given in Supplemental Table S1, with the variations in a single parameter, as specified. Solid lines: $2 \times$ Supplemental Table S1 value; broken lines: Supplemental Table S1 value; dotted line: $0.5 \times$ Supplemental Table $\mathrm{S} 1$ value. $A: K_{\mathrm{m}, \mathrm{PEP}, \mathrm{GAP}} ; B: K_{\mathrm{FBP} \text { ase }} ; C$ : $K_{\mathrm{F}-6-P, \mathrm{PFK}} ; D: K_{\mathrm{F}-1,6-P_{2}, \mathrm{PK}}$.
A

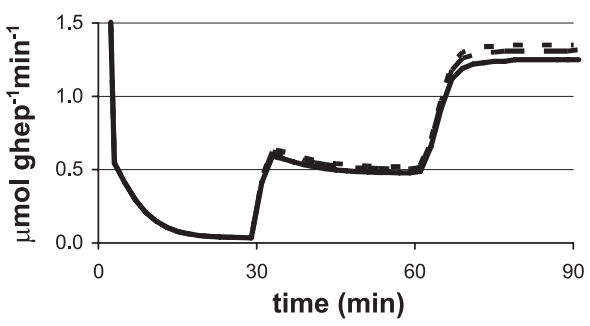

B

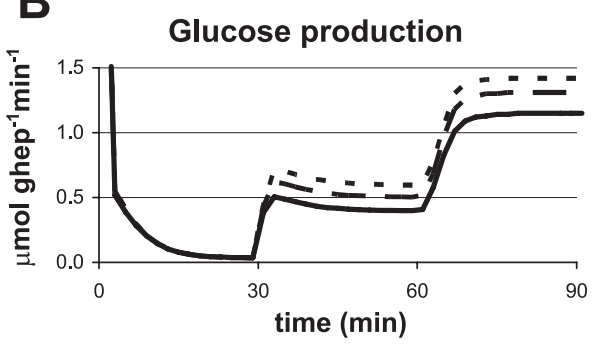

C
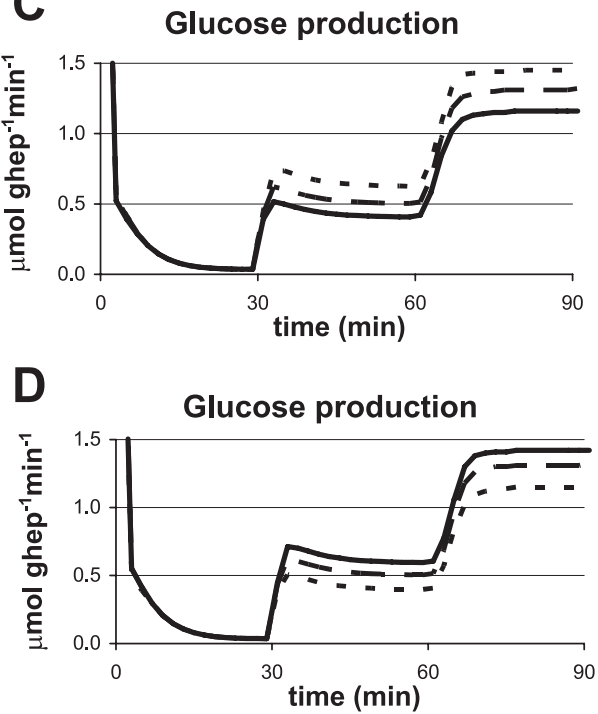

Lactate uptake

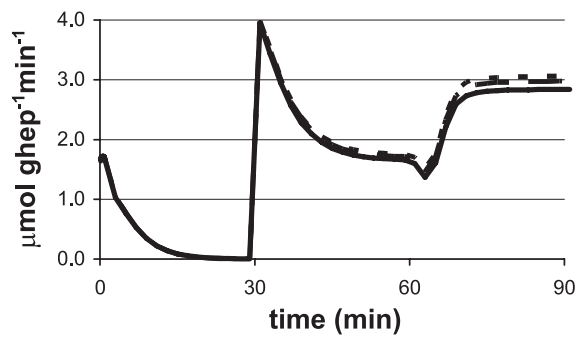

Lactate uptake

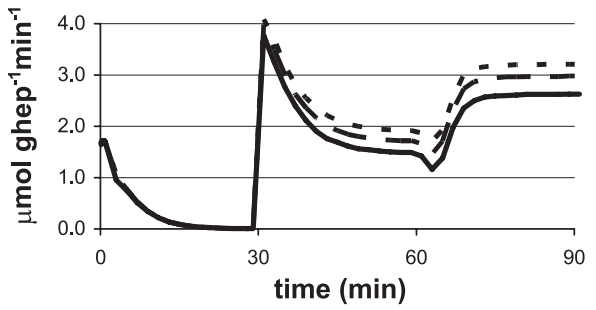

Lactate uptake

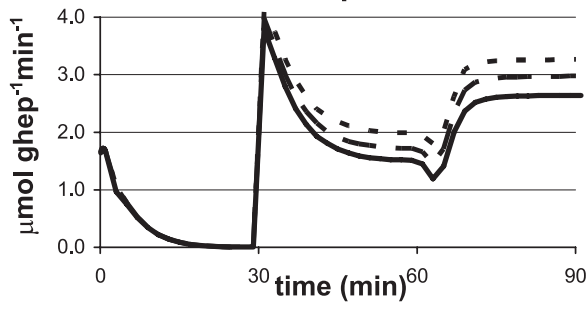

Lactate uptake

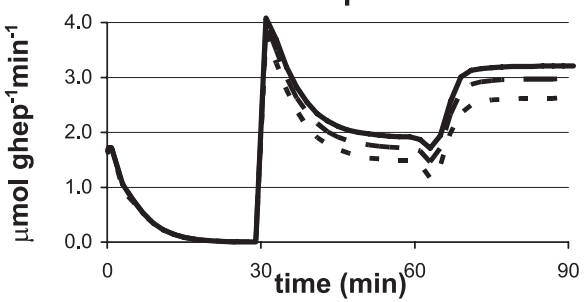

The response time from the antegrade perfusions (36) was slower, with the steady state not achieved within $15 \mathrm{~min}$ of lactate perfusion.

\section{DISCUSSION}

The aim of this study was to develop a model capable of representing the complexity of gluconeogenesis and lipid metabolism and their interactions in the liver. Parameter values were determined from a combination of in vitro enzyme kinetics and data obtained from in vivo fasted rats. One set of experimental perfusion data from Williamson et al. (64) were used for fine tuning parameters (Fig. 3). This model was then independently validated by comparison of model predictions with data obtained from 10 different experiments from 7 different publications.

The glucose production and lactate uptake rates obtained from our simulation are in excellent agreement with the values reported by Williamson et al. (Fig. 3). These values are 50\% lower than those reported by Ross et al. $(51,52)$ and Exton and
Park (20), with this difference partially attributed to the use of red blood cells in the perfusion medium by both of these groups. This could lead to higher rates of oxidative phosphorylation and thus energy availability for gluconeogenesis. The higher gluconeogenic rates have also been attributed by Exton and Park to the possible presence of an activator such as glucagon in the faction $\mathrm{V}$ albumin used in their perfusion medium $(20,64)$. Furthermore, Exton and Park used a different, nonrecycling perfusion system.

Conversion to glucose accounts for $60 \%$ of lactate uptake (Fig. 3); the remaining $40 \%$ is converted to AcCoA through PDC. This latter rate of conversion is in good agreement with the Williamson data, with the small difference because our model assumes negligible pyruvate formation during perfusion with lactate. The endogenous fatty acid oxidation and the PDC flux constitute the source of AcCoA. Compared with the experimental data $(20,51,52,65)$, our simulation overestimates AcCoA conversion to ketone bodies and underestimates its oxidation via the TCA cycle. The low ratio of TCA/ 


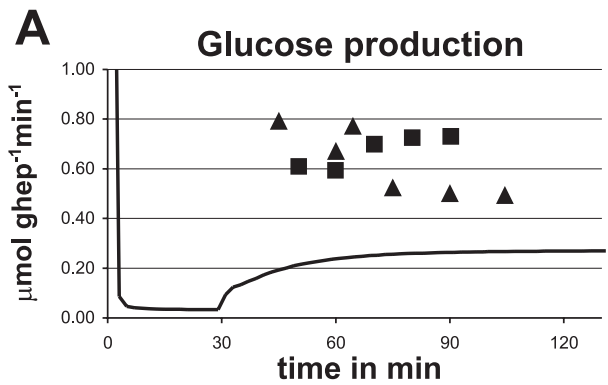

BHB release

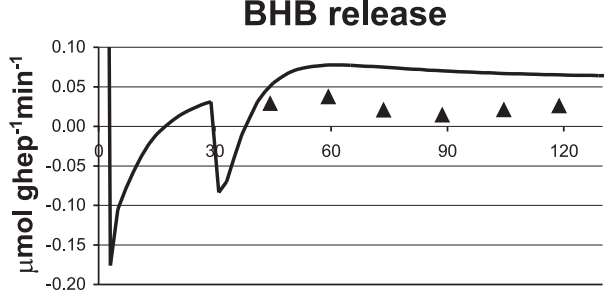

time in $\min$

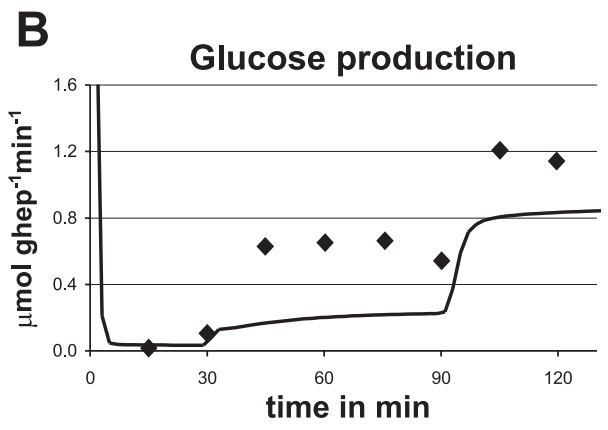

Pyruvate uptake
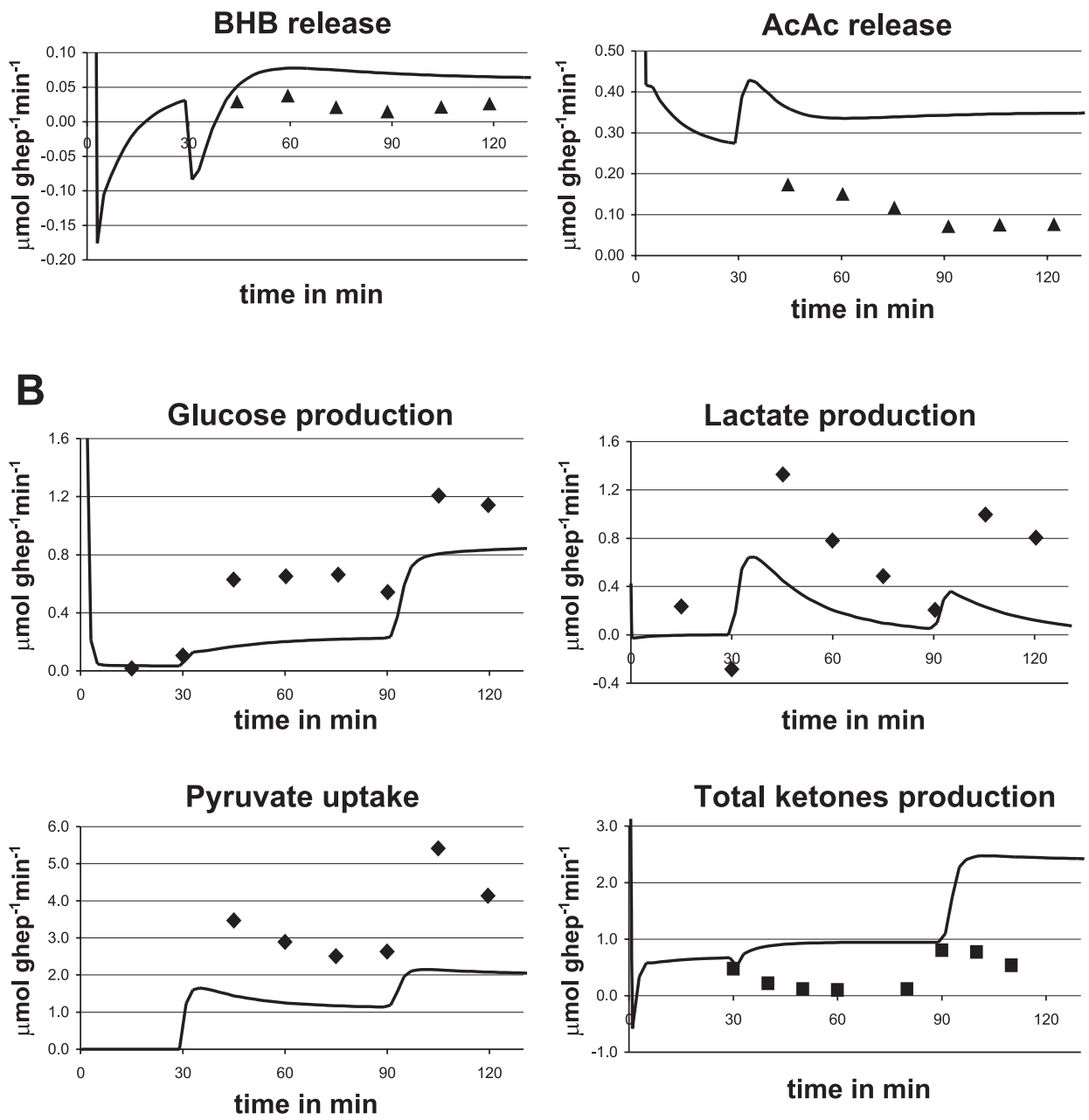

Fig. 5. Gluconeogenic fluxes calculated from perfusion model using pyruvate as the substrate. Rats were fasted for $24 \mathrm{~h}$ before perfusion. Symbols are experimental data from the literature from perfused fasted livers, using a perfusion medium of Krebs-Henseleit bicarbonate buffer with $4 \%$ BSA in a recirculated system, with substrate added continuously to the medium. Solid lines are simulations, using Eqs. 1, 3, and 4, with $\mathrm{F}_{\text {perfusate }}=50 \mathrm{ml} / \mathrm{min}$, $\mathrm{V}_{\text {perfusate }}=100 \mathrm{ml}$; simulation details are given in Table 2, and all other parameters are given in Supplemental Table S1. $A$ : $0<t \leq 30$ min: saline preperfusion (no substrate); $30<$ $t \leq 120 \mathrm{~min}:$ PYR perfusion. Experimental data are as follows: from Williamson et al. (67); $\mathbf{\Delta}$, from Williamson et al. (63). B: $0<$ $t \leq 30$ min: saline preperfusion (no substrate); $30<t \leq 90$ min: PYR perfusion; $90<t \leq$ 120 min: PYR + FA perfusion. Experimental data are as follows: $\bullet$, from Williamson et al. (64); $\mathbf{n}$, from Williamson et al. (67). ketogenesis could contribute to a shortage of NADH; however, it does not inhibit gluconeogenesis, since the NADH that is required for gluconeogenesis is presumably provided by lactate dehydrogenase.

A significant amount of futile cycling is calculated to occur through the PK-PC system during lactate perfusion, with $60 \%$ of the carbon through PC recycled through PK (Fig. 3). This probably overestimates the actual amount of recycling, but there is considerable disagreement in the literature as to the actual extent of recycling. Experiments on livers from fasted rats, perfused with various labeled substrates (pyruvate, alanine, propionate), yielded PK recycling values of $26-45 \%(21,31,42)$. Earlier studies using isolated hepatocytes incubated with lactate have reported PK recycling of $<10 \%$ (50). In vivo studies with $\left[{ }^{13} \mathrm{C}\right]$ lac- tate or $\left[{ }^{13} \mathrm{C}\right]$ propionate have reported higher $\mathrm{PK}$ recycling rates, 45-53\% (31, 33, 35). More recently, Jin et al. (30) used a combination of $\left[{ }^{13} \mathrm{C}\right]$ propionate and $\left[3,4-{ }^{12} \mathrm{C}\right]$ glucose to determine an in vivo $\mathrm{PK}$ recycling of $70 \%$; however, this high $\mathrm{PK}$ recycling value could be attributed to the amount of glucose infused, which could reflect a change in nutritional state of the animal.

The addition of fatty acids to the perfusion medium stimulates gluconeogenesis from lactate, perfectly matching the experimental data (Fig. 3). Moreover, fatty acids also increase the activity of PC and inhibit the activity of PDC, presumably via generation of $\mathrm{AcCoA}$ and $\mathrm{NADH}$. The inclusion of the regulatory terms for $\mathrm{AcCoA}$ in the kinetic expressions for these two enzymes is essential for achieving the correct rate of lactate uptake and gluconeogenesis. 

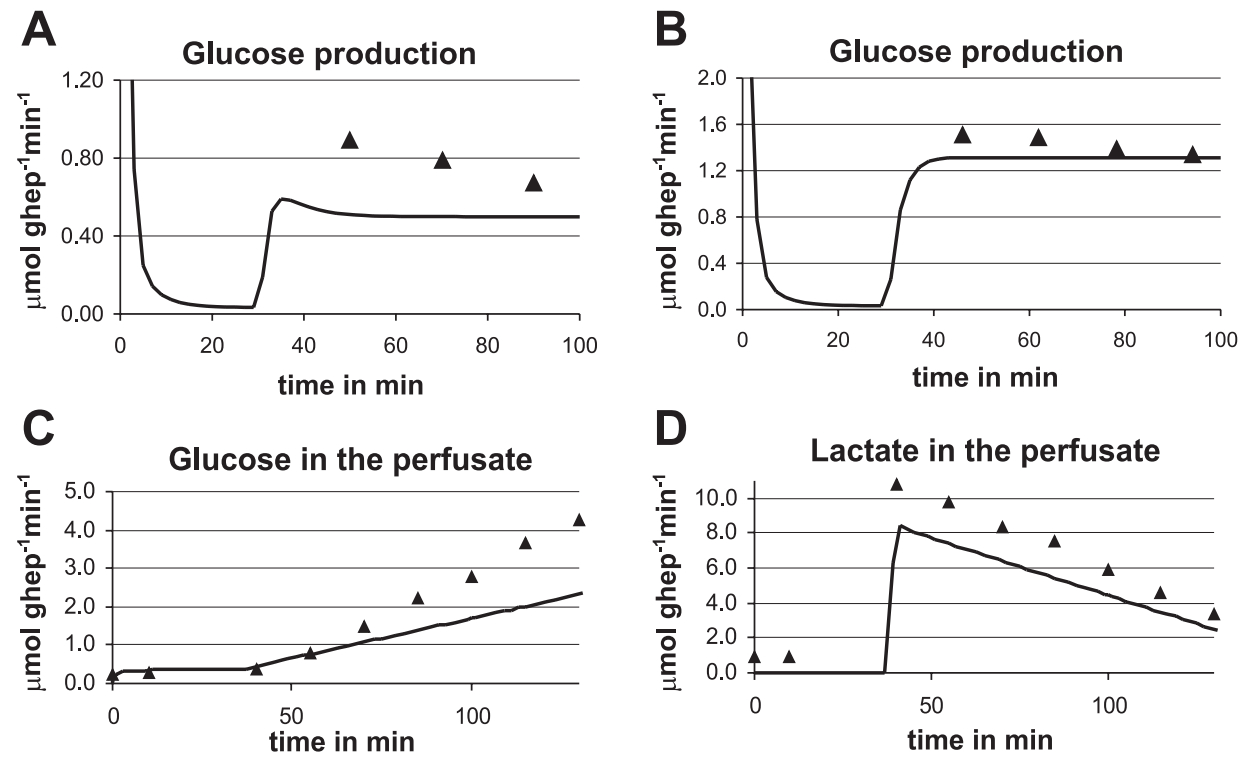

Fig. 6. Gluconeogenic fluxes calculated from perfusion model using lactate as the substrate. Rats were fasted for $24 \mathrm{~h}$ before perfusion. Symbols are experimental data from the literature from perfused fasted livers, using a perfusion medium of Krebs-Henseleit bicarbonate buffer with BSA, and washed human erythrocytes in a recirculated system. Solid lines are simulations using Eqs. 1, 3, and 4, and parameters are as given in Supplemental Table S1. A: $0<t \leq 30$ min: saline preperfusion (no substrate); $30<t \leq 100 \mathrm{~min}$ : lactate $(10 \mathrm{mM})$ perfusion with substrate added continuously to the medium. $\mathbf{\Delta}$, From Frohlich and Wieland (22); simulations calculated with $\mathrm{F}_{\text {perfusate }}=7 \mathrm{ml} / \mathrm{min}$ and $\mathrm{V}_{\text {perfusate }}=100 \mathrm{ml} . B: 0<t \leq 30 \mathrm{~min}$ : saline preperfusion (no substrate); $30<t \leq 100$ min: lactate $(10$ $\mathrm{mM})+$ FA perfusion. $\mathbf{\Delta}$, From Frohlich and Wieland (22); simulations calculated with $\mathrm{F}_{\text {perfusate }}=9 \mathrm{ml} / \mathrm{min}$ and $\mathrm{V}_{\text {perfusate }}=100 \mathrm{ml} . C$ and $D: 0<t \leq 38$ min: saline preperfusion (no substrate); $38<t \leq 100 \mathrm{~min}$ : lactate $(10 \mathrm{mM})$. Symbols are experimental data from perfused fasted livers, with substrate added as a single dose. $\mathbf{\Delta}$, From Hems et al. (27); solid lines are simulations with $\mathrm{F}_{\text {perfusate }}=20 \mathrm{ml} / \mathrm{min}$ and $\mathrm{V}_{\text {perfusate }}=100 \mathrm{ml}$.

In the pyruvate perfusions, the simulated glucose-to-pyruvate ratios (Fig. 5) are very similar to the average of $45 \%$ reported from various researchers $(20,38,51,52,58,64,65$, 67 ), although the calculated rates of pyruvate uptake and glucose production are generally $\sim 50 \%$ lower than that observed experimentally. The rate of pyruvate uptake is determined by several factors, among them, the rate of endogenous fatty acid oxidation $\left(\mathrm{R}_{\mathrm{FA} \text {-endo }}\right)$. In the absence of information specific to the pyruvate perfusion, the rate $\mathrm{R}_{\mathrm{FA}-\text { endo }}$ was set to the same values used for lactate perfusion. A simulated increase in $\mathrm{R}_{\mathrm{FA} \text {-endo }}$ increases pyruvate uptake and glucose production (data not shown), although not to the extent observed experimentally. The simulations yield 6\% conversion of pyruvate to lactate; this value compares well with the $8 \%$ reported by Williamson et al. (64).

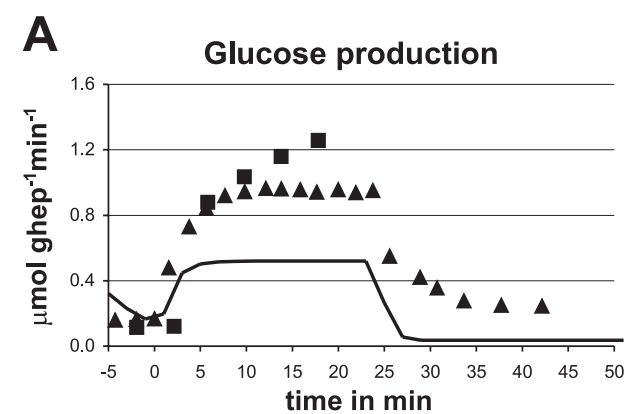

Pyruvate oxidation through PDC plays a major role during the perfusion of pyruvate alone, since it provides the necessary NADH and ATP (along with endogenous fatty acid oxidation) required for conversion of pyruvate to glucose. Our simulation shows that $40 \%$ of pyruvate uptake is channeled through PDC in the absence of exogenous fatty acid (data not shown), which is in good agreement with an average of $30 \%$ reported previously $(20,38,51,52,58)$. The addition of fatty acids to the perfusion medium containing $2 \mathrm{mM}$ pyruvate results in an inhibition of pyruvate oxidation to a value of $5 \%$ of pyruvate uptake, in agreement with the $9 \%$ measured experimentally (38). This finding demonstrates again the importance of AcCoA, induced by the exogenous fatty acid addition, on the control of PDC and the subsequent control of hepatic gluconeogenesis.

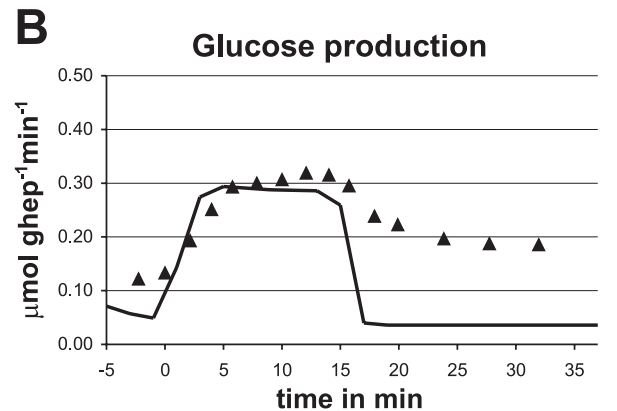

Fig. 7. Gluconeogenesis from lactate and pyruvate in the livers of fasted rats. Solid lines are fluxes calculated from perfusion model using Eqs. 1,3 , and 4 with $\mathrm{F}_{\text {perfusate }}=32 \mathrm{ml} / \mathrm{min}$. All other parameters are as given in Supplemental Table S1. Symbols are experimental data from the literature from fasted livers perfused with Krebs-Henseleit bicarbonate buffer saturated with a mixture of oxygen and carbon dioxide. A: liver was preperfused for 10 min, followed by lactate infusion for $24 \mathrm{~min}$, followed by perfusion with buffer (no substrate) for another $20 \mathrm{~min}$. $\mathbf{\Delta}$, From Bracht et al. (9) using a nonrecirculated retrograde perfusion; $\mathbf{m}$, from Martins et al. (36) using a nonrecirculated anterograde perfusion. $B$ : liver was preperfused for 10 min, followed by pyruvate infusion for 14 min, followed by perfusion with buffer (no substrate) for another $20 \mathrm{~min}$. $\mathbf{\Lambda}$, from Bracht et al. (9) using nonrecirculating, retrograde perfusion. 
Our model also allows the prediction of dynamic and steadystate responses of the liver to various substrates. As shown in Fig. 7, the predicted transient responses to both lactate and pyruvate infusions are very similar to that observed experimentally by Bracht et al. (9), although in the former case, the model underestimated the steady-state glucose production by $\sim 45 \%$. It is unclear why the results from Martins et al. (36) exhibit significantly slower dynamics than that of Bracht et al. (9). The calculated response to pyruvate perfusion (Fig. $5 B$ ) is characterized by a rapid (1 $\mathrm{min}$ ) response in pyruvate uptake and glucose and lactate production. However, after $5 \mathrm{~min}$, the rate of lactate formation begins to decrease, accompanied by a slight reduction of the rate of pyruvate uptake and a gradual increase in glucose production over $30 \mathrm{~min}$. Very similar dynamics have been observed in the experimental data of Williamson et al. (64), also shown in Fig. 5B. This transient behavior results from the balance between a very fast transport rate (of both pyruvate and lactate), a fast lactate dehydrogenase reaction, and relatively slower PC kinetics (data not shown), which causes some of the initial pyruvate influx to drain out as lactate before the gluconeogenic rate has a chance to increase.

The effects of glucagon and insulin were considered in the model indirectly, via cAMP, which is one of the main mediators of hormonal action in the liver. The concentration of cAMP appears directly in the kinetic expressions for FBPase and indirectly through the allosteric constant Lp for PK (Supplemental Table S1). Moreover, cAMP affects the concentration of F-2,6- $P_{2}$, which is included in PFK and FBPase kinetics (Supplemental Table S1). Our study was limited to the fasted state; therefore, the concentrations of cAMP and F-2,6- $P_{2}$, and the allosteric constant $\mathrm{Lp}$, were fixed at values obtained from fasted rats.

Because of the large number of reactions involved in liver metabolism, many of the reactions in series were lumped together. For example, the reactions of PC, malate dehydrogenase, and phosphoenolpyruvate carboxykinase (PEPCK) were lumped together into the reaction labeled $\mathrm{R}_{\mathrm{PYR} \rightarrow \mathrm{PEP}}$, with representation by the kinetics of PC. The kinetics of PC was selected since this enzyme is allosterically regulated by AcCoA, which is critical for correctly describing the interaction between fatty acid uptake and gluconeogenesis. On the other hand, PEPCK is important since it can influence the GTP-to-GDP ratio, which is critical for TCA cycle flux. However, there are no known allosteric regulators of PEPCK, and, despite the rapid change in PEPCK mRNA, the activity of the enzyme is slow to change in response to diet or hormones (the enzyme has a half-life of $6 \mathrm{~h}$ ). Furthermore, control analysis has demonstrated that the major regulation of hepatic gluconeogenesis is distributed among several steps, including PC, inhibition of PK, F-1-6- $P_{2}$, and steps outside the classic gluconeogenic pathway.

In conclusion, the model presented in this paper is a promising tool to study the relationship between gluconeogenesis and lipid metabolism and their role in various metabolic disorders. The model predicts with reasonable accuracy the effect of lipids on many of the metabolic fluxes in the liver. After modifying the kinetic expressions used for the TCA cycle and ketogenesis and extending the model to include gluconeogenesis and urea formation from amino acids, such as alanine, it should serve as an in silico representation of an important component of hepatic metabolism.

\section{ACKNOWLEDGMENTS}

Technical assistance from Nichelle Davis, Parag Pande, and Florin Pusca and constructive comments from Dr. Gerald Saidel are gratefully acknowledged.

\section{GRANTS}

This work was supported by the Center for Modeling Integrated Metabolic Systems [National Institutes of Health (NIH) Grant P50-GM-066309], the Biomedical and Health Institute at Cleveland State University, and by NIH Grant DK-25541 to R. W. Hanson.

\section{REFERENCES}

1. Achs MJ, Anderson JH, Garfinkel D. Gluconeogenesis in rat liver cytosol. I. Computer analysis of experimental data. Comput Biomed Res 4: 65-106, 1971.

2. Agius L, Alberti KG. Regulation of flux through pyruvate dehydrogenase and pyruvate carboxylase in rat hepatocytes. Effects of fatty acids and glucagon. Eur J Biochem 152: 699-707, 1985.

3. Anderson JH, Achs MJ, Garfinkel D. Gluconeogenesis in rat liver cytosol. II. Computer simulation of control properties. Comput Biomed Res 4: 107-125, 1971.

4. Bantenburg JJ, Olson MS. Regulation of pyruvate dehydrogenase by fatty acid in isolated rat liver mitochondria. J Biol Chem 251: 1364-1370, 1976.

5. Beard DA, Qian H. Thermodynamic-based computational profiling of cellular regulatory control in hepatocyte metabolism. Am J Physiol Endocrinol Metab 288: E633-E644, 2005.

6. Bergman RN, EI Refai M. Dynamic control of hepatic glucose metabolism: studies by experiment and computer simulation. Biomed Eng 3: 411-432, 1975.

7. Bergmeyer HU. Methods of Enzymatic Analysis. New York, NY: Academic, 1974, p. 2265-2290.

8. Bode JC, Zelder O, Rumpelt HJ, Wittkamp U. Depletion of liver adenosine phospahtes and metabolic effects of intravenous infusion of fructose or sorbitol in man and in the rat. Eur J Clin Invest 3: 436-441, 1973.

9. Bracht A, Constantin J, Ishii-Iwamoto EL, Suzuki-Kemmelmeir F. Zonation of gluconeogenesis from lactate and pyruvate in the rat liver studied by means of anterograde and retrograde bivascular perfusion. Biochim Biophys Acta 1199: 298-304, 1994.

10. Brundin $\mathbf{T}$, Wahren $\mathbf{J}$. Influence of a mixed meal on splanchnic and interscapular energy expenditure in humans. Am J Physiol Endocrinol Metab 260: E232-E237, 1991.

11. Calik P, Akbay A. Mass flux balance-based model and metabolic flux analysis for collagen synthesis in the fibrogenesis process of human liver. Med Hypotheses 55: 5-14, 2000.

12. Chalhoub E, Xie L, Balasubramanian V, Kim J, Belovich J. A distributed model of carbohydrate transport and metabolism in the liver during rest and high-intensity exercise. Ann Biomed Eng 35: 474-491, 2007.

13. Chan C, Hwang D, Stephanopoulos GN, Yarmush M, Stephanopoulos G. Application of multivariate analysis to optimize function of cultured hepatocytes. Biotechnol Prog 19: 580-598, 2003.

14. Chien D, Dean D, Saha AK, Flatt JP, Ruderman NB. Malonyl-CoA content and fatty acid oxidation in rat muscle and liver in vivo. Am J Physiol Endocrinol Metab 279: E259-E265, 2000.

15. Christian R, Christian D. Changes in availability of glucogenic and ketogenic substrates and liver metabolism in fed and starved states. Ann Nutr Metab 27: 57-70, 1983.

16. Cohen SM. Effects of insulin on perfused liver from streptozotocindiabetic and untreated rats: ${ }^{13} \mathrm{C}$ NMR assay of pyruvate kinase flux. Biochemistry 26: 573-580, 1987.

17. Diem K, Lentner. Documenta Geigy Scientific Tables (7th ed.). Basel, Switzerland: Geigy, 1970.

18. Ekdahl KN, Ekman P. The effect of fructose-2,6-bisphosphate and AMP on the activity of phosphorylated and unphosphorylated fructose-1,6bisphosphatase from rat liver. FEBS Lett 167: 203-209, 1983.

19. Engel PC, Dalziel K. The equilibrium constants of the glutamate dehydrogenase systems. Biochem J 105: 691-695, 1967.

20. Exton JH, Park CR. Control of gluconeogenesis in liver. I. General features of gluconeogenesis in the perfused livers of rats. J Biol Chem 242: 2622-2636, 1967. 
21. Freidman B, Goodman EH, Saunders HL, Kostos V, Weinhouse S. An estimation of pyruvate recycling during gluconeogenesis in the perfused rat liver. Arch Biochem Biophys 143: 566-578, 1971.

22. Frohlich J, Wieland O. Different actions of glucagon and fatty acids on gluconeogenesis from lactate in the perfused rat liver. Horm Metab Res 4: 171-175, 1972.

23. Garfinkel L, Kohn MC, Garfinkel D. Computer simulation of the fructose bisphosphatase/phosphofructokinase couple in rat liver. Eur J Biochem 96: 183-192, 1979.

24. Garfinkel D. Simulation of the Krebs cycle and closely related metabolism in perfused rat liver. I. Construction of the model. Comput Biomed Res 4: 1-17, 1971.

25. Garfinkel D. Simulation of the Krebs cycle and closely related metabolism in perfused rat liver. II. Properties of the model. Comput Biomed Res 4: $18-42,1971$

26. Gross RC, Eigenbrodt EH, Farquhar JW. Endogenous triglyceride turnover in liver and plasma of the dog. J Lip Res 8: 114-125, 1967.

27. Hems R, Ross BD, Berry MN, Krebs HA. Gluconeogenesis in the perfused rat liver. Biochem J 101: 284-290, 1966.

28. Hers HG, Shaftingen V. The fructose 6-phosphste/fructose 1,6-bisphosphate cycle. Curr Top Cell Reg 18: 199-209, 1989.

29. Huang M. Saturating concentration for the uptake of free fatty acids and release of ketone bodies in vivo in rat liver. Life Sci 60: 1915-1922, 1997.

30. Jin ES, Jones JG, Merritt M, Burgess SC, Malloy CR, Sherry AD. Glucose production, gluconeogenesis, and hepatic tricarboxylic acid cycle fluxes measured by nuclear magnetic resonance analysis of a single glucose derivative. Anal Biochem 327: 149-155, 2004.

31. Jones JG, Naidoo R, Sherry DA, Jeffrey FMH, Cottam GA, Malloy CR. Measurements of gluconeogenesis and pyruvate recycling in the rat liver: a simple analysis of glucose and glutamate isotopomers during metabolism of $\left[1,2,3-{ }^{13} \mathrm{C}^{3}\right]$ propionate. FEBS Lett 412: 131-137, 1997.

32. Jungermann K, Heilbronn R, Katz N, Sasse D. The glucose/glucose6-phosphate cycle in the periportal and perivenous zone of rat liver. Eur J Biochem 123: 429-436, 1982.

33. Katz J, Wals $\mathbf{P}$, Lee WNP. Isotopomer studies of gluconeogenesis and the Krebs cycle with 13C- labeled lactate. J Biol Chem 268: 25509-25521, 1993.

34. Krebs HA. The redox state of nicotinamide adenine dinucleotide in the cytoplasm and mitochondria of rat liver. Adv Enzyme Regul 5: 409-434, 1967.

35. Magnusson I, Schumann WC, Bartsch GE, Chandramouli V, Kumaran K, Wahren J, Landau BR. Noninvasive tracing of Krebs Cycle metabolism in liver. J Biol Chem 266: 6975-6984, 1991.

36. Martins AG, Constantin J, Bracht F, Kelmer-Bracht AM, Bracht A. The action of extracellular NAD+ on gluconeogenesis in the perfused rat liver. Mol Cell Biochem 286: 115-124, 2006.

37. McClure WR, Hardy H, Wagner M, Cleland WW. Rat liver pyruvate carboxylase II. Kinetic studies of the forward reaction. J Biol Chem 246: 3579-3583, 1971

38. Menahan LA, Wieland $\mathbf{O}$. The role of endogenous lipid in gluconeogenesis and ketogenesis of perfused rat liver. Eur J Biochem 9: 182-188, 1969.

39. Morikawa S, Inubushu T, Takahashi K, Ishii H, Ozawa K. Gluconeogenesis and phosphoenergetics in rat liver during endotoxemia. J Surg Res 74: 179-186, 1998.

40. Neese RA, Schwarz JM, Faix D, Turner S, Letscher A, Vu D, Hellerstein MK. Gluconeogenesis and intrahepatic triose phosphate flux in response to fasting or substrate loads. J Biol Chem 270: 14452-14463, 1995.

41. Nolan RP, Fenley AP, Lee K. Identification of distributed metabolic objectives in the hypermetabolic liver by flux and energy balance analysis. Metab Eng 8: 30-45, 2006.

42. Petersen KP, Cline GW, Blair J, Shulman G. Substrate cycling between pyruvate and oxaloacetate in awake normal and 3,3'-5-triodo-L-thyroninetreated rats. Am J Physiol Endocrinol Metab 267: E273-E277, 1994.
43. Petersen KF, Price T, Cline GW, Rothman DL, Shulman GI. Contribution of net hepatic glycogenolysis to glucose production during the early postprandial period. Am J Physiol Endocrinol Metab 270: E186-E191, 1996.

44. Pilkis SJ, Claus TH, Johanson RA. Hormonal control of cyclic 3's' -amp levels and gluconeogenesis in isolated hepatocytes from fed rats. $J$ Biol Chem 250: 6328-6336, 1975.

45. Pison CM, Chauvin C, Perrault H, Lafond JL, Boujet C, Levere CM. In vivo hypoxic exposure impairs adaptations to a 48 hour fast in rats. Eur Respir J 12: 658-665, 1998

47. Reich JG, Selkov EE. Energy Metabolism of the Cell: A Theoretical Treatise. New York, NY: Academic, 1981, p. 264-270.

48. Reinhart GD, Hartleip SB. Influence of fructose 2,6-bisphosphate and $\mathrm{MgATP}$ on rat liver phosphofructokinase at $\mathrm{pH} 7$ : evidence for a complex interdependence. Arch Biochem Biophys 296: 224-230, 1992.

49. Roberts MS, Rowland M. Correlation between in-vitro microsomal enzyme activity and whole organ hepatic elimination kinetics: analysis with a dispersion model. J Pharm Pharmacol 38: 177-181, 1985.

50. Rognstad R, Katz J. Role of pyruvate kinase in the regulation of gluconeogenesis from L-lactate. J Biol Chem 252: 1831-1833, 1977.

51. Ross BD, Hems R, Krebs HA. The rate of gluconeogenesis from various precursors in the perfused rat liver. Biochem J 102: 942-951, 1967.

52. Ross BD, Hems R, Freedland RA, Krebs HA. Carbohydrate metabolism of the perfused rat liver. Biochem J 105: 869-875, 1967.

53. Rossetti L, Giaccari A, Barzilai N, Howard K, Sebel G, Hu. Mechanism by which hyperglycemia inhibits hepatic glucose production in conscious rats. Implications for the pathophysiology of fasting hyperglycemia in diabetes. J Clin Invest 92: 1126-1134, 1993.

54. Salem J, Saidel G, Stanley W, Cabrera M. Mechanistic model of myocardial energy metabolism under normal and ischemic conditions. Ann Biomed Eng 30: 202-216, 2002.

55. Saville BA, Gray MR, Tam YK. Models of hepatic drug elimination. Drug Metab Rev 24: 49-88, 1992.

56. Scrutton M, White D. Pyruvate carboxylase from rat liver: catalytic properties in the absence, and at low concentrations of acetyl-CoA. Biochem Biophys Res Commun 48: 85-93, 1972.

57. Stubs M, Veech RL, Krebs HA. Control of the redox state of the nicotinamide-adenine dinucleotide couple in rat liver cytoplasm. Biochem J 126: 59-65, 1972.

58. Teufel H, Menahan LA, Shipp JC, Boning S, Wieland O. Effect of oleic acid on the oxidation and gluconeogenesis from $1-{ }^{14} \mathrm{C}$ pyruvate in the perfused rat liver. Eur J Biochem 2: 182-186, 1967.

59. Torres NV. Modelizaton and experimental studies on the control of the glycolytic-glycogenolytic pathway in rat liver. Mol Cell Biochem 132: 117-126, 1994.

60. Tucker GA, Dawson AP. The kinetics of rat liver and heart mitochondrial-hydroxybutyrate dehydrogenase. Biochem J 179: 579-581, 1979.

61. Uyeda K, Furuya E, Luby IJ. The effect of natural and synthetic D-fructose 2,6-bisphosphate on the regulatory kinetic properties of liver and muscle phosphofructokinases. J Biol Chem 256: 8394-8399, 1981.

62. Van Schaftingen E, Hue L, Hers HG. Study of the fructose 6-phosphate/ fructose 1,6-bi-phosphate cycle in the liver in vivo. Biochem $J$ 192: 263-271, 1980.

63. Williamson JR, Anderson J, Browning ET. Inhibition of gluconeogenesis by butymalonate in perfused rat liver. J Biol Chem 245: 1717-1726, 1970.

64. Williamson JR, Browning ET, Scholz R. Control mechanisms of gluconeogenesis and ketogenesis. I. Effects of oleate on gluconeogenesis in perfused rat liver. J Biol Chem 244: 4607-4616, 1969.

65. Williamson JR, Browning ET, Scholz R. Control mechanisms of gluconeogenesis and ketogenesis. II. Interactions between fatty acid oxidation and the citric acid cycle in perfused rat liver. J Biol Chem 244: 4617-4627, 1969.

66. Williamson DH, Lund P, Krebs HA. The redox state of free nicotinamide-adenine dinucleotide in the cytoplasm and mitochondria of rat liver. Biochem J 103: 514-527, 1967.

67. Williamson JR, Rostand SG, Peterson MJ. Control factors affecting gluconeogenesis in perfused rat liver. J Biol Chem 245: 3242-3251, 1970. 